\title{
Sounding-derived parameters associated to tornadic storms in Catalonia
}

\author{
Author: Oriol Rodríguez i Ballester. \\ Facultat de Física, Universitat de Barcelona, Diagonal 645, 08028 Barcelona, Spain*.
}

\begin{abstract}
We study several parameters that are calculated from soundings in order to relate them with tornadic storms in Catalonia. We look for differentiate between non tornadic thunderstorms soundings, waterspout soundings and tornado soundings with those parameters. In addition, we compare our results to other author's results to analyse if they are similar.
\end{abstract}

\section{INTRODUCTION}

Catalonia is the region of the Iberian Peninsula where there are more tornadoes [1]. Every year, between 3 and 4 tornadoes cause damages in fields, isolated farms, woods and urban areas. These tornadoes are not as strong as in the USA: usually they are EF0 or EF1, and occasionally are EF2 (only the $11 \%$ of the tornadoes registered between 2001 and 2014). However, historically there have been some tornadoes that have caused important damages, as in Badalona in 1892 or l'Espluga de Francolí in 1994. Although there are studies of the space-temporally tornadoes distribution in Catalonia [2] and exhaustive studies about specific episodes of severe weather in this area [3], [4], there are not studies about sounding-derived parameters associated to tornadic storms. In other regions the relation between these parameters and the formation of tornadoes has been studied, for example in the Netherland [5] or in California [6]. Thus, seeing the lack of an exhaustive study of these characteristics in Catalonia, we have analysed several sounding-derived parameters for different weather type-days. In this way we can check whether there is any significant relation between these parameters and the tornado or waterspout formation, so as to establish thresholds that indicate us if there are special conditions for tornado or waterspout formation. We have based our research on the studies that had been done in other regions. We wanted to compare the parameters values for different weather-soundings. We made a classification composed by four types of day:

- dry days (DD): day without precipitation

- $\quad$ non tornadic thunderstorm days (NTTD): one or more reports of lightning in a radius of $10 \mathrm{~km}$ around Barcelona and no tornadoes nor waterspouts.

- $\quad$ waterspout days (WD): one or more waterspouts detected. If a waterspout had damage in land, we will consider it WD, too.

- tornado days (TD): one or more tornadoes detected. If during the same day a tornado and a waterspout appeared, we also will consider it TD.

We thought it was appropriate to distinguish between waterspouts and tornadoes to analyse if there is any difference in the sounding-derived parameters.

\section{DATA AND METODOLOGY}

\section{A. Sounding database}

In 2008 we started to build a database of tornadoes that had affected Catalonia since 2001. We consulted scientific articles, media, forums about severe weather and we talked with experts. From 2001 to 2014, 45 tornadoes (11 of them were waterspouts in their beginning) had affected the country. It means that we have had 29 tornado-days and 4 waterspout-days with damages in land. We have got most soundings from the University of Wyoming Department of Atmospheric Science website. We have obtained the rest of these soundings thanks to the Meteorological Service of Catalonia and Joan Arús, a meteorologist from the Spanish Meteorology Agency (AEMET) who provided us some of the soundings that were not available on the net. In some cases it has not been possible to get soundings (as for example in the tornado from 12 November 2005 in Vallfogona de Balaguer) so we have not taken it into account in this work. In total we have collected 40 DD soundings, 40 NTTD soundings, 17 WD soundings and 23 TD soundings.

\section{B. Sounding selection}

For WD and TD we needed to associate each meteorological event with a representative sounding of the event. To do this, we have applied the proximity-inflow method that Rasmussen and Blanchard (1998) [7] exposed. This method consists on defining an inflow sector through the soundings where it should be located the meteorological event, choosing the sounding that satisfies both conditions of proximity and wind direction. Firstly, we discarded any sounding that was further than $400 \mathrm{~km}$ of the event. Then, we have looked for the average of the wind components in the lowest $500 \mathrm{~m}$ to find out which was the direction of the air mass movement. If the event was within $\pm 75^{\circ}$ of the mean wind vector we selected the sounding. After that, if there were two or more soundings that satisfied these conditions, we would take the sounding with the maximum CAPE. It would be better to choose soundings that were launched close to the event, in the same moment that it occurred. However, these restrictive conditions would have made impossible to have a large enough number of soundings to complete our database. This is because in Catalonia there is only one sounding station located in Barcelona and it only launches two soundings per day, at 00 UTC and at 12 UTC. For DD we have consulted the weather station's summaries around Barcelona, searching 40 days without any type of precipitation and then we have taken the sounding of Barcelona for each of these days. As for NTTD, we have looked for the lightning detector archive of Catalonia's Meteorological Centre (SMC) and we have saved 40 soundings of the days when it has been detected one or more electric flash in a radius of $10 \mathrm{~km}$ around Barcelona. When we have ordered and classified all the data-soundings in independent archives we have used RAOB, software program 
that plots Skew-T diagrams and calculates several derivedsounding parameters. Finally, it would be very interesting to study the wind shear. However RAOB cannot provide us with this information. For this reason we have made a program that enables us to calculate wind shear between the surface and the altitude of $6 \mathrm{~km}$.

\section{Parameters studied}

Sounding derived parameters are not enough to predict storms and even less tornadoes [7,8]. Most of these indexes are not governed by any physical law, as they are empirical. For the storm-genesis we need three ingredients: lift, moisture and instability. The indexes are only tools to identify some of these conditions. We have been collecting data for each day of 18 sounding-derived parameters, and we have made more than 30 graphs, but we only are going to expose the most interesting ones for our study. Convective Available Potential Energy (CAPE in $\mathrm{J} \mathrm{kg}^{-1}$ ) is the energy that an air parcel that is near the surface has to rise along the atmosphere. While it ascends it expands adiabatically. If it becomes positively buoyant with respect to its surrounding it will be accelerated upward until the parcel temperature becomes lower than its surroundings temperature. The CAPE's mathematical expression is [8]:

$$
\mathrm{CAPE}=\mathrm{g} \int_{\mathrm{LFC}}^{\mathrm{EL}} \frac{\theta_{\mathrm{p}}-\theta}{\theta} \mathrm{dz}
$$

where $\mathrm{g}$ is the acceleration due to gravity, EL is the equilibrium level of the parcel, LFC is the level of free convection of the parcel, $\theta_{\mathrm{p}}$ is the potential temperature of the parcel and $\theta$ is the potential temperature of the environment. Regarding wind shear (WS06 km in $\mathrm{m} \mathrm{s}^{-1}$ ), it is defined as the difference of the wind vector module between two different levels, in our case, between $6 \mathrm{~km}$ high $\left(\mathrm{w}_{6 \mathrm{~km}}\right)$ and on the surface $\left(\mathrm{w}_{\mathrm{s}}\right)[5]$ :

$$
\mathrm{WS} 06 \mathrm{~km}=\mathrm{w}_{6 \mathrm{~km}}-\mathrm{w}_{\mathrm{s}}
$$

Higher values of wind-shear avoid the coupling of storm updraft and downdraft. This helps to storm-genesis and increases its duration.

Another important factor that we have to take into account is the storm-relative helicity (SRH in $\mathrm{m}^{2} \mathrm{~s}^{-2}$ ). It is a measure of the potential to create rotation in a cyclonic updraft [5]:

$$
\mathrm{SRH}=-\int_{0}^{\mathrm{h}} \mathbf{k} \cdot\left[\left(\mathbf{w}_{\mathbf{H}}-\mathbf{c}\right) \times \frac{\partial \mathbf{w}_{\mathbf{H}}}{\partial \mathrm{z}}\right] \mathrm{dz}
$$

where $\mathbf{k}$ is the upward unit vector, $\mathbf{w}_{\mathbf{H}}$ is the horizontal wind vector, $\mathbf{c}$ is the motion vector of the storm and $\mathrm{h}$ is the top of the air layer where we calculate SRH. Usually, and in our work too, $\mathrm{h}$ is $3 \mathrm{~km}$. The Energy Helicity Index (EHI in $\mathrm{m}^{4} \mathrm{~s}$ ${ }^{4}$ ) is the combination of two indexes, CAPE and SRH. It mixes the instability and the helicity [7]:

$$
\mathrm{EHI}=\frac{\mathrm{CAPE} \cdot \mathrm{SRH}}{160000}
$$

We have studied the EHI for the air layer comprised between $0 \mathrm{~km}$ and $2 \mathrm{~km}$. The Severe Weather Threat Index (SWEAT) evaluates the potential for severe weather by examining both kinematic and thermodynamic information along low-level and middle-level troposphere. It includes several parameters into the same index:

$$
\begin{array}{r}
\text { SWEAT }=12 \mathrm{Td}_{850}+20(\mathrm{TT}-49)+2 \mathrm{w}_{850}+\mathrm{w}_{500} \\
+125\left[\sin \left(\mathrm{wd}_{500}-\mathrm{wd}_{850}\right)+0.2\right]
\end{array}
$$

where $\mathrm{Td}_{850}$ is the dew point at $850 \mathrm{hPa}$, TT is the Total Totals Index (defined by $\mathrm{TT}=\mathrm{T}_{850}+\mathrm{Td}_{850}-2 \mathrm{~T}_{500}$, where $\mathrm{T}$ is temperature and $\mathrm{Td}$ is the dew point), $\mathrm{w}$ is the wind speed (in knots) and wd is the wind direction (in deg.). Finally, the Bulk Richardson Number (BRN) is a dimensionless index that consists in evaluating the equilibrium between the instability and the wind shear in a thunderstorm environment, and it is defined as [8]:

$$
\mathrm{BRN}=\frac{\mathrm{CAPE}}{0.5\left(\overline{\mathrm{u}}^{2}+\overline{\mathrm{v}}^{2}\right)}
$$

where $\bar{u}^{2}$ and $\bar{v}^{2}$ are the square of the difference of the wind components between $6 \mathrm{~km}$ attitude and $500 \mathrm{~m}$ above the surface.

\section{Sounding-derived parameters analysis}

\section{A. Convective Available Potential Energy (CAPE)}

In Fig. 1 we can observe that TD soundings, with the median nearby $800 \mathrm{~J} \mathrm{~kg}^{-1}$, have a larger median value than NTT and WD soundings. DD soundings, as expected, have the lowest median value, around $350 \mathrm{~J} \mathrm{~kg}^{-1}$. CAPE, as we have explained, is the potential energy that an air parcel has for rising. In order to ascend the parcel is necessary some trigger mechanism. If there is not any one, CAPE can be very high, but the air parcel will not rise. This explains why there are some DD with large CAPE values. Whatever, there are more TD soundings with CAPE greater than $3000 \mathrm{~J} \mathrm{~kg}^{-1}$ than for the other sounding categories.
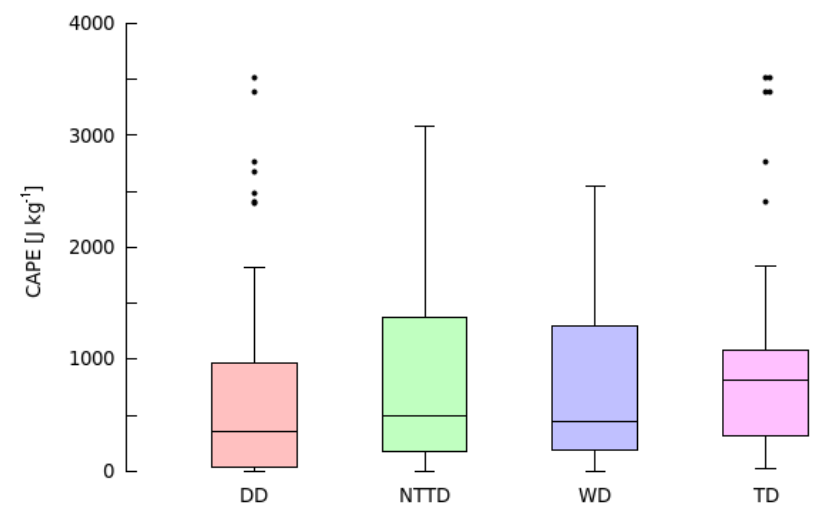

FIG. 1. Box plots of CAPE distribution values for different types of soundings. 
(a)
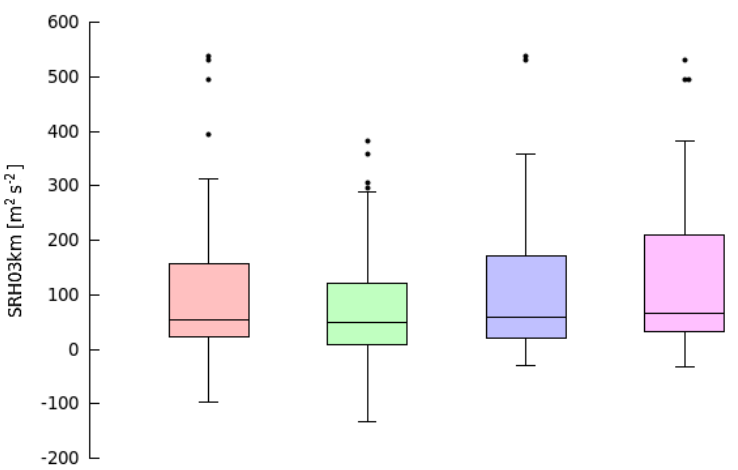

TD

(c)

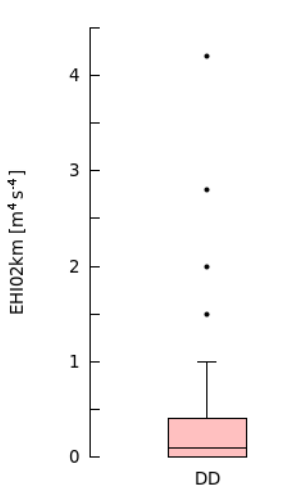

$$
\text { (5) }
$$

(e)
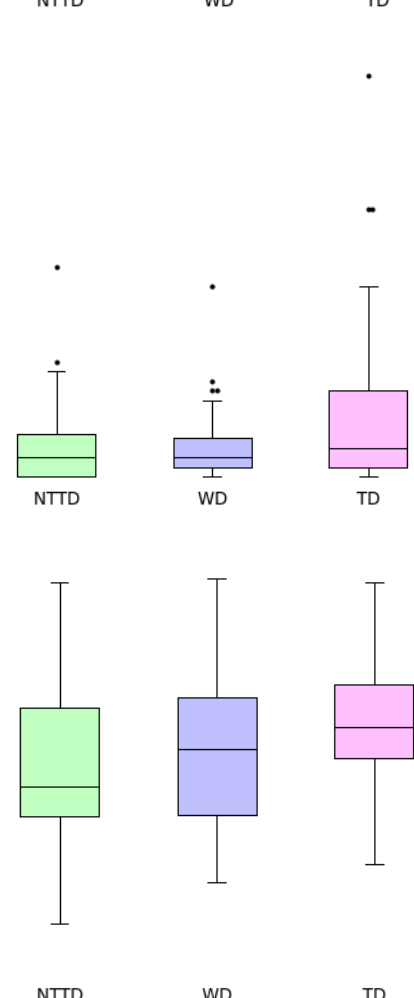

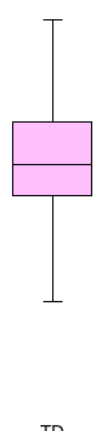

TD

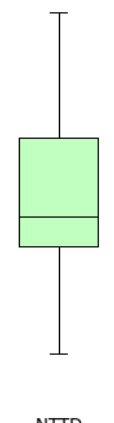

NTTD (b)
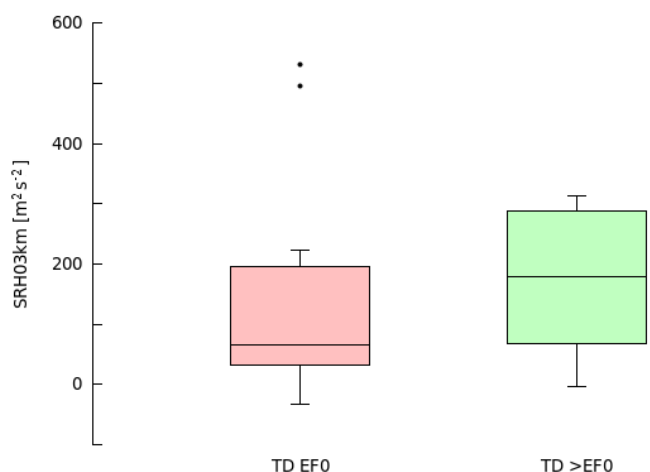

(d)
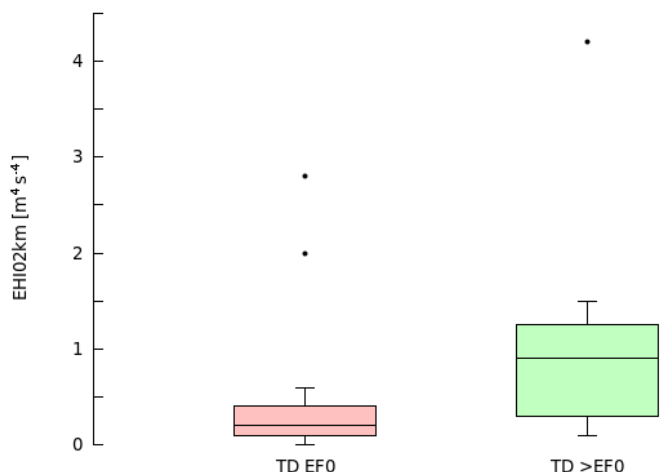

(f)

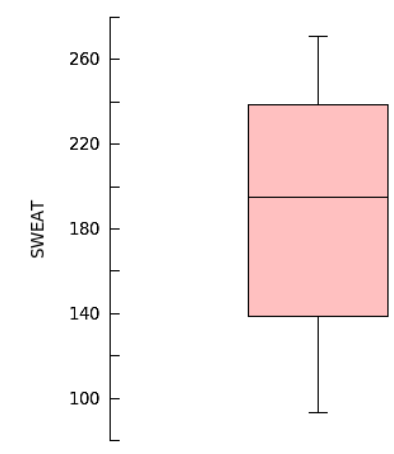

TD EFO
TD > EFO

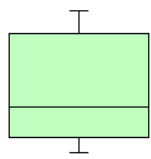

TD $>$ EFO

FIG. 2 (a) Box plots of SRH distribution values for different types of soundings. (b) Box plots of SRH distribution values for EF0 tornado and >EF0 tornado soundings. (c) Box plots of EHI distribution values for different types of soundings. (d) Box plots of EHI distribution values for EF0 tornado and >EF0 tornado soundings. (e) Box plots of SWEAT Index distribution values for different types of soundings. (f) Box plots of SWEAT Index distribution values for EF0 tornado and >EF0 tornado soundings.

\section{B. Storm-relative Helicity 0 - 3 km (SRH)}

As we can observe in Fig. 2.a., SRH is similar for TD and WD soundings, with a median value around $65 \mathrm{~m}^{2} \mathrm{~s}^{-2}$. The median for DD is a little bit lower, $55 \mathrm{~m}^{2} \mathrm{~s}^{-2}$. It is not obvious to see the difference, but if we look a little more closely at the $75^{\text {th }}$ percentile we will see better this dissimilarity. For TD, the $75^{\text {th }}$ percentile value is higher than $200 \mathrm{~m}^{2} \mathrm{~s}^{-2}$, while for DD and NTTD is between $130 \mathrm{~m}^{2} \mathrm{~s}^{-2}$ and $160 \mathrm{~m}^{2} \mathrm{~s}^{-2}$. For $\mathrm{WD}$, the $75^{\text {th }}$ percentile is slightly higher, around $180 \mathrm{~m}^{2} \mathrm{~s}^{-2}$. We can see a bigger difference if we compare soundings of days with tornadoes of EF0 intensity and days with tornadoes more intense (>EF0). In Fig. 2.b. we can check that the median for the former is $71 \mathrm{~m}^{2} \mathrm{~s}^{-2}$, whereas for the latter is $179 \mathrm{~m}^{2} \mathrm{~s}^{-2}$, a clearly superior number. It is caused because stronger tornadoes need more important rotation to achieve high wind speeds.

\section{Energy Helicity Index 0 - 2 km (EHI)}

In Fig. 2.c. is obvious that EHI for TD soundings is mostly higher than for the rest of soundings. Whilst median value is relatively similar for all the sounding categories, the $75^{\text {th }}$ percentile is notably higher for TD than the rest of the weather type-soundings. But over all we have to highlight that there are some TD soundings with $2.5 \mathrm{~m}^{4} \mathrm{~s}^{-4}$ to $4 \mathrm{~m}^{4} \mathrm{~s}^{-4}$ EHI values, which denotes large CAPE and SRH. Comparing EHI between EF0 tornadoes and >EF0 tornadoes it is very clear that large CAPE and SRH are necessary for the formation of EF1 or EF2 tornadoes, as we can see in the equation (5). Almost the $25^{\text {th }}$ percentile of TD $>$ EF0 sounding is higher than $75^{\text {th }}$ percentile of TD EF0 sounding, what demonstrates the importance of the rotating and ascending capacity of the air for the formation of strong tornadoes. 


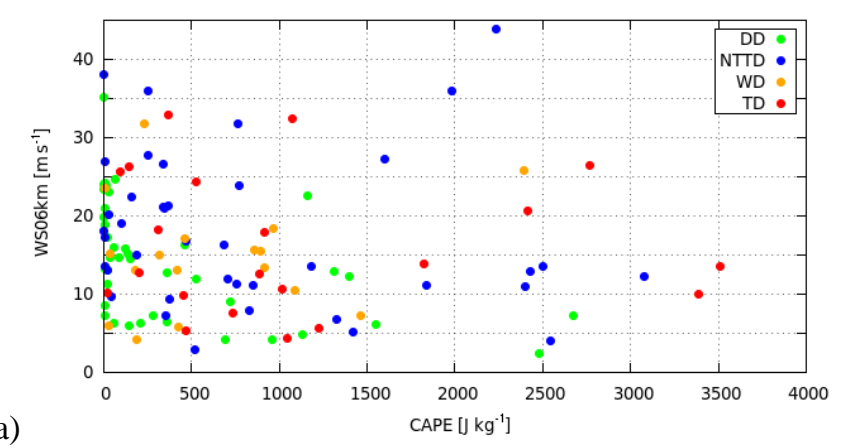

(a)

FIG. 3. (a) Scatter diagram CAPE vs. WS06km of sounding representing DD, NTTD, WD and TD. (b) Scatter plot SRH/BRNSHR vs. BRNSHR. The line distinguishes between tornadic and nontornadic thunderstorms, according to Stensrud et al. [8].

\section{Severe Weather Threat Index (SWEAT)}

SWEAT Index, together with EHI, are the parameters with which show clearly differences between every weather type soundings. As it can be seen in Fig. 2.e. for DD the median value is 122 , while for NTTD is 163 . If we attend to WD we will see that the median value is 193, and for TD soundings is 210. As a result, this index allows us to predict if thunderstorms may spawn waterspouts or tornadoes. Also distinguishing between EF0 tornado days and >EF0 tornado days we can distinguish the difference in all the percentile values, especially for $25^{\text {th }}$ percentile and the median. The lowest SWEAT Index value found for an EF1 or superior tornado is 119 , while we can see that it is not rare to have EF0 tornadoes with 100 to 140 SWEAT Index values.

\section{E. CAPE vs. WS06km}

Rasmussen and Blanchard [7] made a graph with CAPE in $\mathrm{x}$-axis and WS06km in y-axis to look how the soundings were situated in it. They wanted to check if there was any difference between the weather-days type. In addition, they searched if it would be possible to delimitate higher concentration areas of tornado and nonsupercell thunderstorm sounding. In the CAPE vs. WS06km plot is easily verifiable that most of DD are focused on low-levels of CAPE as we expected, because the atmosphere is more stable than in storm-days. Despite that fact, DD soundings can take high WS06km values, up to $25 \mathrm{~m} \mathrm{~s}^{-1}$. Most of NTTD are situated in CAPE values around $0 \mathrm{~J} \mathrm{~kg}^{-1}$ to $1500 \mathrm{~J} \mathrm{~kg}^{-1}$, and between 5 $\mathrm{m} \mathrm{s}^{-1}$ and $30 \mathrm{~m} \mathrm{~s}^{-1}$ WS06km. WD, and especially TD, they fall in larger CAPE and WS06km values, around 100 - $1500 \mathrm{~J}$ $\mathrm{kg}^{-1}$ and 7 - $26 \mathrm{~m} \mathrm{~s}^{-1}$. Comparing with figure 9 [7] we can see that the TD distribution is relatively similar. There, they range from 500 to $2700 \mathrm{~J} \mathrm{~kg}^{-1}$ CAPE and 10 to $28 \mathrm{~m} \mathrm{~s}^{-1}$ WS06km. But we must remember that Rasmussen and Blanchard only consider significant tornadoes (>EF2), whereas we have taken into account all tornado cases. We think that this is the principal reason why CAPE and WS06km have larger values on tornado-days. Also for NTTD soundings (nonsupercell thunderstorms in their case), are mostly confined between 0 to $1500 \mathrm{~J} \mathrm{~kg}^{-1}$ CAPE and 1 to 23 $\mathrm{m} \mathrm{s}^{-1}$ WS06km.

\section{F. BRNSHR vs. SRH/BRNSHR}

The objective of Stensrud, Cortinas and Brooks [8] was to discriminate between tornadic and nontornadic thunderstorm.
So in fact, the tornadoes that they had in consideration were supercellular tornadoes. To do that, they represented in a graph the sounding values of SRH/BRNSHR vs. BRNSHR. BRNSHR is defined by the denominator of the equation (6), so we can rewrite it as:

$$
\text { BRNSHR }=\frac{\text { CAPE }}{\text { BRN }}
$$

It is obviously that BRNSHR contains information of the wind shear and, as Stensrud et al. [8] comment, it has been found a high correlation between BRNSHR and the maximum vertical vorticity. It is from that graph that they could establish a separation line for tornadic and nontornadic thunderstorms. Over this line there are most tornadic thunderstorm soundings and under it there are most nontornadic thunderstorm cases. We have made the same figure with our soundings and we have copied their separation line (Fig. 3.b.). To do it, we calculated BRNSHR with values of CAPE and BRN that RAOB gave us for each NTTD, WD and TD sounding. We have discerned between EF0 tornadoes and $>$ EF0 tornadoes. From Fig. 3.b. it can be seen that most of TD $>$ EF0 tornado soundings are situated near or over the separation line. Only 4 of $13 \mathrm{TD}>\mathrm{EF} 0$ soundings are under it. EF0 tornado and waterspout soundings are concentred under the line, between $10 \mathrm{~m}^{2} \mathrm{~s}^{-2}$ and $60 \mathrm{~m}^{2} \mathrm{~s}^{-2}$ BRNSHR and between -0.5 and $4 \mathrm{SRH} /$ BRNSHR. NTTD soundings are more scattered and they are underline, as expected. If we compare with figure 1.a. [8] we will see that we coincide in TD $>$ EF0 and NTTD soundings distribution. They also have some tornado cases under the line, as we do. But there is a clear difference between both graphs with WD and EF0. Firstly, because they didn't take into consideration waterspouts. And, secondly, because they only considered supercellular tornadoes, which are usually stronger than nonsupercellullar tornadoes. We have not done the differentiation between supercellular and nonsupercellular tornadoes. So, as they didn't consider nonsupercellular tornadoes, we do not know whether our graphs would coincide or not if they would have taken into account nonsupercellular tornadoes. Looking at our graph, where we have considered nonsupercellular tornadoes, it seems possible that this kind of tornadoes could be situated underline, because they do not need such extreme conditions. 


\section{CONCLUSIONS}

- As stated in [6], [7] and [8], we have seen that individual parameters for themselves do not predict categorically thunderstorms, waterspouts or tornadoes. We have checked that it is possible to have large CAPE in absence of thunderstorms, or high SRH values in calmed days. So they are useful tools to know if there are possibilities of a tornado, waterspout o thunderstorm formation. Nevertheless we have to know always what the synoptic and mesoscale meteorological conditions are.

- We have checked that CAPE, SRH, EHI and SWEAT Index for TD are higher than for NTTD.

- We consider that a threshold is the limit above which there are $75 \%$ of the phenomenon cases $\left(25^{\text {th }}\right.$ percentile). Attending to this, we can propose the following thresholds for SWEAT Index to differentiate between NTTD and TD:

\begin{tabular}{|l|c|}
\hline Sounding type & SWEAT \\
\hline NTTD & 135 \\
\hline TD & 185 \\
\hline
\end{tabular}

TABLE I: SWEAT Index thresholds $\left(25^{\text {th }}\right.$ percentile) for NTTD and TD.

Also we can establish thresholds for SWEAT Index and SRH for TD EF0 and TD >EF0:

\begin{tabular}{|l|c|c|}
\hline Sounding type & SWEAT & SRH $\left(\mathrm{m}^{2} \mathrm{~s}^{-2}\right)$ \\
\hline TD EF0 & 138 & 30 \\
\hline TD $>$ EF0 & 215 & 80 \\
\hline
\end{tabular}

TABLE II: SWEAT Index and SRH thresholds $\left(25^{\text {th }}\right.$ percentile) for TD EF0 and TD >EF0.

- The median value of the indexes is more clear to distinguish between NTT and TD than with $25^{\text {th }}$ percentile:

\begin{tabular}{|l|c|c|c|c|}
\hline $\begin{array}{l}\text { Sounding } \\
\text { type }\end{array}$ & $\begin{array}{c}\text { CAPE } \\
\left(\mathrm{J} \mathrm{kg}^{-1}\right)\end{array}$ & SWEAT & $\begin{array}{c}\text { EHI } \\
\left(\mathrm{m}^{4} \mathrm{~s}^{-4}\right)\end{array}$ & $\begin{array}{c}\text { SRH } \\
\left(\mathrm{m}^{2} \mathrm{~s}^{-2}\right)\end{array}$ \\
\hline NTTD & 502 & 163 & 0.2 & 49 \\
\hline TD & 825 & 210 & 0.4 & 67 \\
\hline
\end{tabular}

TABLE III: CAPE, SWEAT Index, EHI and SRH median value for TD EF0 and TD >EFO.

- Generally there are few differences between parameter values for NTTD and WD. Only for SRH we can find higher values for WD that for NTTD.

- Although we do not have so many tornado day soundings as other authors, we can say that our results are similar, as we can see in Fig. 10 and Fig. 11. The significant fact is that they used to consider only strong tornadoes or supercellular tornadoes whereas we have studied all tornado reports. Nonetheless, the thresholds that they obtained are higher than our thresholds.

- Due to the rather small number of tornadoes that have occurred during the last 14 years (45 in total), there are not so many soundings to analyse. It would be interesting in the future to complete this study with more tornado and waterspout cases. Moreover, it would be interesting to differentiate between supercell tornadoes and nonsupercell tornadoes to see which is the most habitual in Catalonia.

\section{Acknowledgments}

First of all, I would like to thank Joan Bech (TFG supervisor) for all the help given to me along the elaboration of the final degree project. This work would not have been possible without his experience and his advices. I also want to thank Joan Arús (AEMet) and Roger Vendrell (SMC) for their help to get some soundings that they were not publicly available. I would not overlook the help of Miquel Gayà and Salvador Castán in completing the Catalonia's tornadoes database. And, of course, I want to thank Marta Baldrís, Roser Saperas and Ignacio Ballesteros for the support that they have given me along the project elaboration.
[1] M. Gayà, «Tornadoes and severe storms in Spain», Atmos. Res., vol. 100, pp. 334-343, 2011.

[2] M. Gayà et al., «Tornadoes and waterspouts in Catalonia», Nat. Hazards and Earth Syst. Sci., vol. 11, pp. 1875-1883, 2011.

[3] J. Bech et al., «An observational study of the 7 September 2005 Barcelona tornado outbreak», Nat. Hazards and Earth Syst. Sci., vol. 7, pp. 129-139, 2007.

[4] J. Bech et. al, «A Mediterranean nocturnal heavy rainfall and tornadic event. Part I: Overview, damage survey and radar analysis», Atmos. Res., vol. 100, pp. 621-637, 2011.

[5] P. H. Groenemeijer and A. van Delden, «Soundingderived parameters associated with large hail and tornadoes in the Netherlands», Atmos. Res., vol. 83, pp. 473-487, 2007.

[6] J. P. Monteverdi et al., «Shear Parameter Thresholds for Forecasting Tornadic Thunderstorms in Northern and Central California», Weather Forecast., vol. 18, pp. 357-370, 2003.

[7] E. N. Rasmussen and D. O. Blanchard, «A Baseline Climatology of Sounding-Derived Supercell and Tornado Forecast Parameters», Weather Forecast., vol. 13, pp. 1148-1164, 1998.

[8] D. J. Stensrud et al., «A Baseline Climatology of Sounding-Derived Supercell and Tornado Forecast Parameters», Weather Forecast., vol. 12, pp. 613632, 1997. 